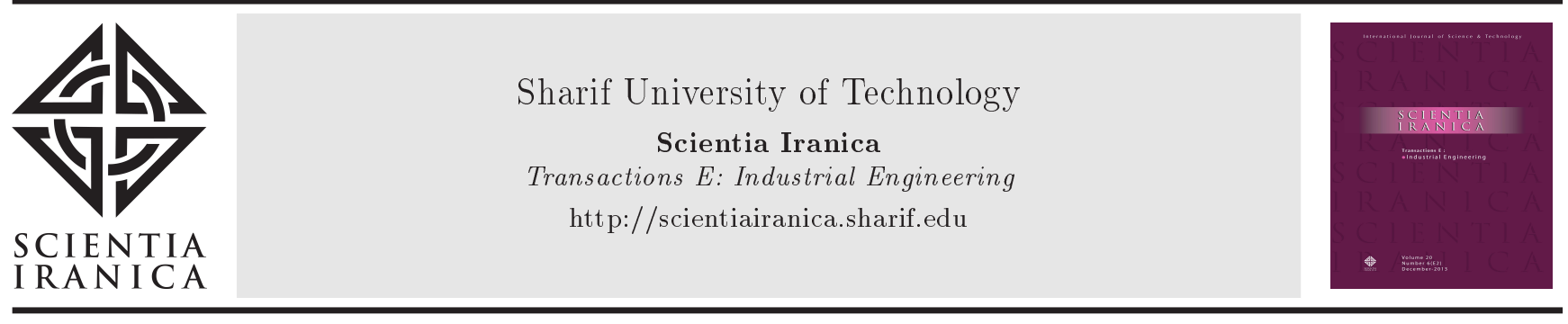

\title{
Study of the correlation between oil price and exchange rate under the new state of the economy
}

\author{
S. Mao, Q. He*, X. Xiao, and C. Rao \\ School of Science, Wuhan University of Technology, Wuhan 430070, P. R. China.
}

Received 17 March 2017; received in revised form 6 September 2017; accepted 30 April 2018

\section{KEYWORDS}

Grey system;

$G M(q, N, \tau)$ model;

Time-delay grey

correlation analysis;

Particle swarm

optimization;

New state of economy.

\begin{abstract}
Aiming at solving the problem of small sample modeling of oil price and exchange rate with time-delayed causality, a grey multivariate time lag model and its solution are proposed against the new economic background of economic development, structural optimization, and power conversion. Considering the difficulty of solving qorder differential equations analytically, we obtain a numerical solution. On the basis of this solution, the validity of the model is proved. The numerical results show that the model can describe and predict the operating rules of oil price and exchange rate economic systems with time delay, and it is concluded that the development of oil price and exchange rate is not coordinated under the new state of the economy. The relationship between oil prices and the exchange rate has changed; in this state, oil prices have a positive effect on the rise of the exchange rate.

(C) 2019 Sharif University of Technology. All rights reserved.
\end{abstract}

\section{Introduction}

Since oil is one of the most important commodities in the world, the fluctuation of oil prices will have an important impact on a country's economy. Oil is priced in US dollars. Obviously, the exchange rate and oil prices are naturally linked. Under the new economic situation, in order to ensure a more stable economic and financial environment, the correlation between oil prices and exchange rates should be analyzed very carefully.

Many studies have been done by domestic and foreign scholars to study the relationship between oil prices and exchange rate. In the direction of conduction, Amano \& Norden [1], Akram [2], Huang \& Guo [3]

*. Corresponding author. Tel.: +8615527823804 E-mail addresses: maosh-415@163.com (S.Mao); hq_0603@126.com (Q.He); xiaoxp@263.net (X.Xiao); cjrao@163.com (C.Rao)

doi: $10.24200 /$ sci. 2018.20448 and Babatunde [4] suggested that changes in oil prices could cause changes in exchange rates. In contrast, Sadorsky [5], Yousefi \& Wirjanto [6], Nakajima \& Hamori [7] and Beckmann \& Czudaj [8] supposed that changes in the exchange rates could cause fluctuations in oil prices. In addition, Reboredo [9], Aloui et al. [10], Bal \& Rath [11] and Brayek et al. [12] proposed a two-way causal relationship between oil prices and exchange rates. In the research of Krichene [13] and Zalduendo [14], the authors used the Vector Error Correction Model (VECM) to study the correlation between oil prices and exchange rate. Ghosh [15] used India's 2007-2008 data to study the relationship between oil prices and exchange rate and established an indexed generalized autoregressive conditional heteroskedasticity (GARCH) model in which increases in oil prices lead to lower exchange rates. Basher et al. [16] used the Granger test method to derive the one-way Granger causality from oil prices to exchange rates. Shahbaz et al. [17], Reboredo \& Rivera-Castro [18] and Yang et al. [19] used wavelet decomposition to study the dependence of oil prices and major currencies on 
US dollar. They found that oil prices and exchange rates were independent in the pre-crisis period and that changes in oil prices during the post-crisis period would cause fluctuations in exchange rate. Reboredo et al. [20] used the Detrended Cross-Correlation Approach (DCCA), and found that the negative correlation between oil and dollar increased after the global financial crisis in 2008. Jiang \& $\mathrm{Gu}$ [21] and $\mathrm{Li}$ et al. [22] proposed MF-DCCA and MF-ADCCA to research the asymmetry between oil price and US dollar exchange rate, showing that their asymmetric degree is obvious. Mensah et al. [23] examined the relationship between oil price and US dollar exchange rates for some oildependent economies by cointegration test, suggesting a long-run equilibrium relationship between oil price and exchange rate, especially for currencies of the key oil-exporting countries. Tiwari \& Albulescu [24] and Jammazi et al. [25] applied wavelet coherence and Granger-causality tests to the research of oil price and exchange rate, which showed that the effect of exchange rate on oil price was different for long-term and shortterm periods; this outcome is similar to our conclusions. The present paper establishes a grey model to study the correlation between oil price and exchange rate.

For the new economic period, the symmetrical state of the economic structure, i.e., the pursuit of economic structure on the basis of symmetry of sustainable economic development through the study of the relationship between economic variables, can better guide one in real life. According to the Macroeconomic Analysis and Forecasting Task Force [26] of People's University of China, 2015 is a major year for China's reforms and adjustments, and it is also a year when the "new normal" of China's economy entered the "Attack period". The relationship between oil price and exchange rate is of practical significance. The relationship between economic variables is often complicated, containing many factors that fluctuate with oil prices, and we are only studying data with small sample sizes. If an autoregressive model is created directly, a large error is generated. The grey system model is generated by accumulating the stochastic sequence, which is based on the generation and applied to small sample data. Under many conditions, high simulation accuracy and prediction accuracy can achieve better effects for applications. Therefore, this paper studies the relationship between oil prices and exchange rate under the new economic normal condition by establishing a fractional-order, $\operatorname{GM}(q, N, \tau)$, model.

Deng [27] first put forward the multi-variable grey $G M C(1, N)$ model, which is a grey model for a linear dynamic model of multiple variables. It uses the time sequence of multiple variables as its basis. Changes in trend variables, known to affect the situation, can also predict the system variables' behavior. Liu et al. [28] provided an approximate whitening time response of the $G M(1, N)$ model. Xiao et al. [29] studied the influence of multiplier conversion on $G M(1, N)$ model parameters, and Xiao \& Mao [30] and Xiao et al. [31] promoted and discussed grey models that work in different situations. Tien [32] proposed the $G M C(1, N)$ model to obtain the model values as a typical solution. With the grey control coefficient added to the model, it can significantly improve the accuracy of the predictions made by multiple grey model. In addition, in order to better apply the model, Tien proposed three improved models based on the original model. Qiu and Liu [33] studied the problem of discretizing the $G M(1, N)$ model based on the sampling theorem and state transition matrix. Huang and Guo [34] extended the $G M(1,1 \mid \tau, r)$ model to the multivariables $G M(1, N \mid \tau, r)$ model for the temporal relationship between the input and output of the real system. The model parameters were solved by a group algorithm. Wang [35] performed nonlinear processing with the relevant variables of the model and introduced the power exponent to reflect the non-linear effects of the relevant variables on the system's behavior variables, thus creating the power model and reducing the modeling error. By using matrix decomposition, the fractional grey model can be solved. Further, it is proved to be better than $G M(1,1)$ model [36-37].

According to Figure 1, the data fluctuation of oil price and exchange rate can be observed clearly. In this paper, based on the above research, the asynchronous prices, and exchange rate volatility in practice, the lag period is introduced into the $G M(1, N)$ model [30]. The traditional $G M(1, N)$ model is an integer order accumulation. To lessen the random error in the sequence data and expand the scope of the model, the fractional accumulation is introduced and fractional differential equations are established. This results in a fractional order $\operatorname{GM}(q, N, \tau)$ model that enables us to better study the correlation between oil prices and the

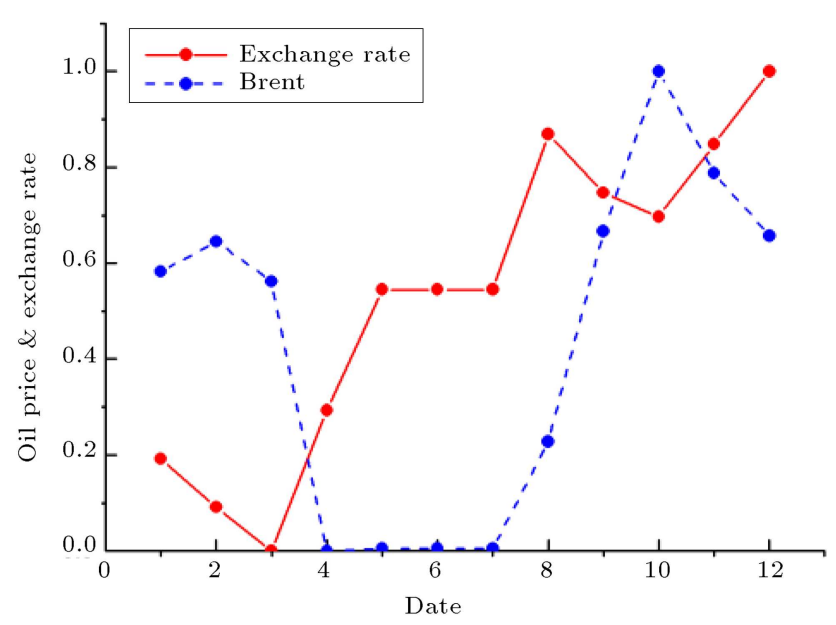

Figure 1. Fluctuations of oil price and exchange rate. 
Table 1. Symbol description.

\begin{tabular}{cl}
\hline Symbol & \multicolumn{1}{c}{ Description } \\
\hline$q$ & Order of differential equations \\
$N$ & Number of variables \\
$\tau$ & Lag number \\
$r$ & Cumulative number of times \\
$P$ & 1st order accumulated generating matrix \\
$P^{r}$ & $r$ th order cumulative generating matrix \\
$x^{(0)}$ & Raw data of $x$ sequence \\
$x^{(r)}$ & $r$ times-accumulated $x$ sequence \\
$y$ & Behavior variable \\
$x_{v}$ & $v$ th factor variable \\
\hline
\end{tabular}

exchange rate under the new economic development. This model shows that the relationship between oil prices and the exchange rate is not harmonious, and increases in oil prices influence the exchange rate. To better read the article, the description of symbols is shown in Table 1.

\section{Problem description}

There is a co-integration relationship between oil price and exchange rate. To study this relationship, an attempt has been made to establish models quantitatively with a mathematical method. Further, only the data with small sample sizes are studied. If an autoregressive model is created directly, a large error is generated; thus, grey models are established. This paper improves the traditional $G M(1, N)$ model and puts forward a grey multivariate time lag model.

\subsection{The traditional $G M(1, N)$ model}

The traditional $G M(1, N)$ model [30] is a firstorder linear dynamic model of $N$ variables based on a time series with multiple variables. Let $y^{(0)}=\left(y^{(0)}(1), y^{(0)}(2), \cdots, y^{(0)}(m)\right)^{T}$ be a systemcharacteristic data sequence, also known as a set of behavior variables.

$$
x_{v}{ }^{(0)}=\left(x_{v}{ }^{(0)}(1), x_{v}{ }^{(0)}(2), \cdots, x_{v}{ }^{(0)}(m)\right)^{T}(v=
$$

$1,2, \cdots, N-1)$ is a sequence of factors that are highly correlated with the system's characteristic data sequence, also known as a factor variable. $y^{(1)}$ is a cumulative sequence of original sequence, $y^{(0)} ; x_{v}{ }^{(1)}$ is a cumulative sequence of original sequence; and $x_{v}^{(0)}$ $(v=1,2, \cdots, N-1) . Z_{y}^{(1)}$ generates a sequence for $y^{(1)}$ neighbor mean. The definition of $G M(1, N)$ is:

$$
y^{(0)}(t)+a Z_{y}^{(1)}(t)=\sum_{v=1}^{N-1} b_{v} x_{v}{ }^{(1)}(t),
$$

where $a$ is the development coefficient, reflecting the degree of coordination between exchange rate and oil price; and $b$ is the coordination coefficient, which reflects the influence of the factor variables on the dynamic change of the behavior variables.

\subsection{Fractional-order generation matrix}

For a cumulative accumulation of sequences, $x^{(0)}$ can be written as $x^{(1)}(t)=\sum_{v=1}^{t} x^{(0)}(v)$. Matrix statements can be written as $x^{(1)}=P x^{(0)} . \quad P$ is a cumulative generating matrix.

$$
P=\left[\begin{array}{cccc}
1 & 0 & \cdots & 0 \\
1 & 1 & \cdots & 0 \\
\vdots & \vdots & \ddots & \vdots \\
1 & 1 & 1 & 1
\end{array}\right]
$$

If the original sequence is accumulated for $r(r \geq 2)$ times, it is:

$$
x^{(r)}=P^{r} x^{(0)}
$$

where $P^{r}=\left(p_{s f}^{r}\right)_{n \times n}$ is an $r$ order accumulation matrix, and $r$ is an integer [37]:

$$
\left(p_{s f}{ }^{r}\right)_{n \times n}= \begin{cases}C_{s-f+r-1}^{r-1}=\frac{(s-f+r-1) !}{(r-1) !(s-f) !}, & s \geq f \\ 0, & s<f\end{cases}
$$

Therefore, we obtain the relation shown in Box I. According to this formula, a generalized definition of the number of combinations is used to generalize $P^{r}$. When $r$ is extended from a positive integer to a rational number (fraction), a fractional-order matrix can be obtained [38]. When $r$ is not a positive integer, $P^{r}$ is only a sign, and a fractional-order matrix can be obtained.

$$
P^{r}=\left[\begin{array}{ccccc}
1 & 0 & 0 & \cdots & 0 \\
r & 1 & 0 & \cdots & 0 \\
\frac{r(r+1)}{2 !} & r & 1 & \cdots & 0 \\
\vdots & \vdots & \vdots & \ddots & \vdots \\
\frac{r(r+1) \cdots(r+n-2)}{(n-1) !} & \frac{r(r+1) \cdots(r+n-3)}{(n-2) !} & \frac{r(r+1) \cdots(r+n-4)}{(n-3) !} & \cdots & 1
\end{array}\right]
$$




\section{Grey multivariate time lag model and its solution}

\subsection{Fractional model}

The classic $G M(1,1)$ model accumulates the original data once, while, in the fractional $\operatorname{GM}(q, N, \tau)$ model, the fractional-order generation matrix, $P^{r-q}$, is used instead of the original accumulation in the original model. The obtained model is called the fractional $\operatorname{GM}(q, N, \tau)$ model.

The definition of the fractional $\operatorname{GM}(q, N, \tau)$ model and lag value is as follows.

$G M(q, N, \tau)$ is a multivariable grey model with multi-order and multiple delays; $\operatorname{GM}(q, N, \tau)$ contains a behavior variable, denoted by $y$, and $N-1$ factor variables, denoted by $x, v=1,2, \cdots, N-1$. The time difference between the factor variable and the behavior variable is time lag $\tau$.

Definition 1. Let the data sequence:

$$
y^{(0)}=\left(y^{(0)}(1), y^{(0)}(2), \cdots, y^{(0)}(m)\right)^{T}
$$

be the sequence of the system behavior, sequence:

$$
x_{1}{ }^{(0)}=\left(x_{1}{ }^{(0)}(1), x_{1}{ }^{(0)}(2), \cdots, x_{1}{ }^{(0)}(m)\right)^{T}
$$

be the correlation factor sequence, $x_{v}{ }^{(r)}$ be the $r$ accumulation sequence of $x_{v}{ }^{(0)}$ and:

$$
\begin{aligned}
& x_{v}{ }^{(r)}=A^{r} x_{v}{ }^{(0)}, \\
& y^{(r-q)}=y^{(r-q)}(1), \\
& \left.y^{(r-q)}(2), \cdots y^{(r-q)}(m)\right)^{T}
\end{aligned}
$$

be the $r-q$ accumulation sequence of the system behavior sequence:

$$
y^{(r-q)}=A^{r-q} y^{(0)},
$$

and:

$$
Z_{y}^{(r)}=\left(Z_{y}^{(r)}(2), Z_{y}^{(r)}(3), \cdots, Z_{y}^{(r)}(m)\right)^{T},
$$

where:

$$
Z_{y}^{(r)}(t)=0.5 y^{(r)}(t-1)+0.5 y^{(r)}(t)
$$

The fractional $\operatorname{GM}(q, N, \tau)$ model is:

$$
y^{(r-q)}(t)+a Z_{y}^{(r)}(t)=\sum_{v=1}^{N-1} b_{v} x_{v}^{(r)}(t-\tau) .
$$

Theorem 1. Let $y^{(0)}$ be the system behavior sequence, $x_{v}{ }^{(0)}(v=1,2, \cdots, N-1)$ be the system factor data sequence, $y^{(r)}, x_{v}{ }^{(r)}$ be the $r$ order cumulative generating sequences of $y^{(0)}, x_{v}{ }^{(0)}$, and $Z_{y}{ }^{(r)}$ be the immediately adjacent mean generation sequence of $y^{(r)}$. Eqs. (3) and (4) are shown in Box II. Then, the least squares estimate of parameter column is as follows:

$$
\begin{aligned}
& \hat{\eta}=\left[a, b_{1}, b_{1}, \cdots b_{N-1}\right]^{T}, \\
& \hat{\eta}=\left(H^{T} H\right)^{-1} H^{T} Y .
\end{aligned}
$$

Proof. Importing data into Model (1) results in the following equations:

$$
\begin{aligned}
& y^{(r-q)}(\tau+2)=\sum_{v=1}^{N-1} b_{v} x_{v}{ }^{(r)}(2)-a Z_{y}{ }^{(r)}(\tau+2) \\
& y^{(r-q)}(\tau+3)=\sum_{v=1}^{N-1} b_{v} x_{v}{ }^{(r)}(3)-a Z_{y}^{(r)}(\tau+3) \\
& \vdots \\
& y^{(r-q)}(m)=\sum_{v=1}^{N-1} b_{v} x_{v}{ }^{(r)}(m-\tau)-a Z_{y}^{(r)}(m) .
\end{aligned}
$$

The above equations can be written as $Y=H \hat{\eta}$ for a set of parameter estimates:

$$
\gamma=Y-H \hat{\eta} \text {. }
$$

Then:

$$
\begin{aligned}
& H=\left[\begin{array}{cccc}
-Z_{y}^{(r)}(\tau+2) & x_{1}{ }^{(r)}(2) & \cdots & x_{N-1}{ }^{(r)}(2) \\
-Z_{y}^{(r)}(\tau+3) & x_{1}{ }^{(r)}(3) & \cdots & x_{N-1}{ }^{(r)}(3) \\
\vdots & \vdots & \ddots & \vdots \\
-Z_{y}^{(r)}(m) & x_{1}{ }^{(r)}(m-\tau) & \cdots & x_{N-1}{ }^{(r)}(m-\tau)
\end{array}\right] \\
& Y=\left[\begin{array}{c}
y^{(r-q)}(\tau+2) \\
y^{(r-q)}(\tau+3) \\
\vdots \\
y^{(r-q)}(m)
\end{array}\right] .
\end{aligned}
$$




$$
\begin{aligned}
\omega & =\gamma^{T} \gamma=(Y-H \hat{\eta})^{T}(Y-H \hat{\eta}) \\
& =\sum_{t=\tau+2}^{m}\left(y^{(r-q)}(t)-\sum_{v=1}^{N-1} b_{v} x_{v}{ }^{(r)}(t-\tau)+a Z_{y}{ }^{(r)}(t)\right)^{2}
\end{aligned}
$$

Eq. (7) is made minimum and $a, b_{1}, b_{2}, \cdots, b_{N-1}$ are related as follows:

$$
\begin{gathered}
\frac{\partial \omega}{\partial a}=2 \sum_{t=\tau+2}^{m}\left(y^{(r-q)}(t)-\sum_{v=1}^{N-1} b_{v} x_{v}{ }^{(r)}(t-\tau)\right. \\
\left.+a Z_{y}{ }^{(r)}(t)\right) \cdot Z_{y}{ }^{(r)}(t)=0 \\
\frac{\partial \omega}{\partial b_{1}}=-2 \sum_{t=\tau+2}^{m}\left(y^{(r-q)}(t)-\sum_{v=1}^{N-1} b_{v} x_{v}{ }^{(r)}(t-\tau)\right. \\
\left.\quad+a Z_{y}{ }^{(r)}(t)\right) \cdot x_{1}{ }^{(r)}(t-\tau)=0 \\
\left.\vdots \quad+a Z_{y}^{(r)}(t)\right) \cdot x_{N-1}^{(r)}(t-\tau)=0
\end{gathered}
$$

namely, $H^{T} \cdot \gamma=0, H^{T}(Y-H \hat{\eta})=0$, and $\hat{\eta}=$ $\left(H^{T} H\right)^{-1} H^{T} Y$.

As shown in Figure 2, the steps of establishing and solving the fractional-order gray model are seen. First of all, the data are processed by accumulate generation. Based on Section 2.2, fractional-order generation matrix is proposed; then, matrices $H$ and $Y$ are established. Through the derivation, $B$ and $Y$ can be used to represent the parameters of the model. Next, the differential equation should be solved. Finally, the accuracy of the model can be determined through error calculation.

\section{Definition 2. Let:}

$$
y=(y(1), y(2), \cdots, y(m))^{T}
$$

be the reference time series and:

$$
x_{v}=\left(x_{v}(1), x_{v}(2), \cdots x_{v}(m)\right)^{T}
$$

be the comparison time series. $\tau$ is the lag value of $x_{v}$ relative to $y$, and $l$ is the number of discrete time points $(l \leq m)$. The comparison of time series:

$$
y_{\tau}=(y(1), y(2), \cdots, y(l))^{T}
$$

and:

$$
x_{v \tau}=\left(x_{v}(1), x_{v}(2), \cdots x_{v}(l)\right)^{T}
$$

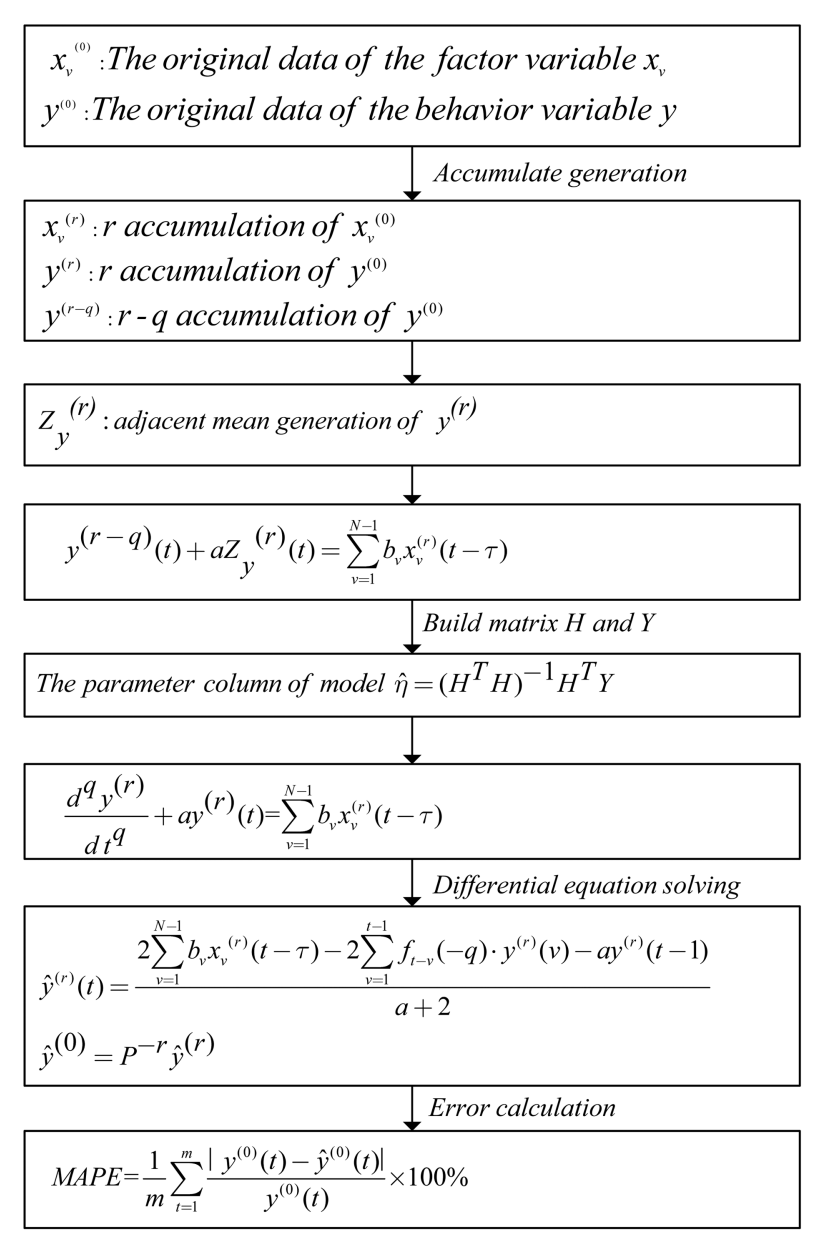

Figure 2. Flow chart of fractional grey model.

with time delay $\tau$ is made. The correlation coefficient between $y_{\tau}$ and $x_{v \tau}$ at the $p$ th point is as follows [30]:

$$
\begin{aligned}
& \xi\left(y(p), x_{v \tau}(p+\tau)\right)=\frac{\Delta_{\min }+\rho \Delta_{\max }}{\Delta_{0 i}(p)+\rho \Delta_{\max }}, p=1,2, \cdots, l \\
& \Delta_{0 v}(p)=\left|y(p)-x_{v}(p+\tau)\right|
\end{aligned}
$$

$\Delta_{0 v}(p)$ is the absolute difference, $\Delta_{\min }$ is the minimum difference between the two poles, $\Delta_{\max }$ is the maximum difference between the two poles, $\rho$ is the resolving coefficient, and $\rho \in(0,1)$, generally, takes $\rho=0.5$. The grey correlation degree between $y_{\tau}$ and $x_{v \tau}$ is:

$$
r_{v}(\tau)=\frac{1}{l} \sum_{p=1}^{l} \xi\left(y(p), x_{v \tau}(p+\tau)\right), \tau=0,1, \cdots, m-l
$$

where $r_{v}\left(\tau^{*}\right)=\max r_{v}(\tau)$. The maximum grey correlation degree that corresponds to the time lag is $y_{\tau}$ and $x_{v \tau}$ of the time delay, denoted by $\tau^{*}$.

Figure 3 shows the determination of the lag. According to Figure 3, the value of the time lag is obtained, which will be applied to Section 4 . 


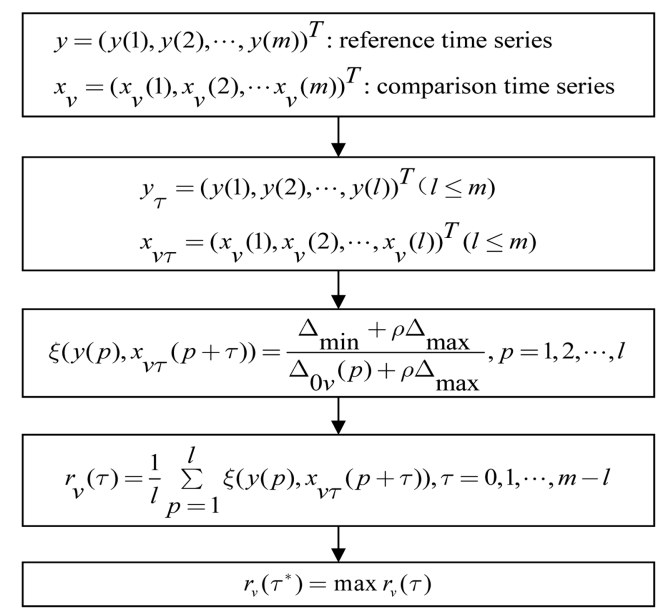

Figure 3. Determination of the lag. model is:

The whitening form of the fractional $\operatorname{GM}(q, N, \tau)$

$$
\frac{d^{q} y^{(r)}}{d t^{q}}+a y^{(r)}(t)=\sum_{v=1}^{N-1} b_{v} x_{v}^{(r)}(t-\tau)
$$

For the differential equation shown in Eq. (11), especially when $q \neq 1$, it is difficult to give an analytical solution. The numerical solution can be calculated according to Eq. (1).

Theorem 2. The solution to the differential equation, as shown in Eq. (2), is obtained by Eq. (12) as shown in Box III. At the same time, the restored value of the sequence can be obtained as follows:

$$
\hat{y}^{(0)}=P^{-r} \hat{y}^{(r)} \text {. }
$$

\section{Proof:}

$$
\begin{aligned}
y^{(r-q)}= & P^{-q} y^{(r)} \\
y^{(r-q)}(t)= & \sum_{v=1}^{t} f_{t-v}(-q) \cdot y^{(r)}(v)=y^{(r)}(t) \\
& +\sum_{v=1}^{t-1} f_{t-v}(-q) \cdot y^{(r)}(v) \\
Z_{y}{ }^{(r)}(t)= & \frac{1}{2}\left(y^{(r)}(t-1)+y^{(r)}(t)\right)
\end{aligned}
$$

$$
\begin{aligned}
y^{(r)}(t) & +\sum_{v=1}^{t-1} f_{t-v}(-q) \cdot y^{(r)}(v) \\
& +\frac{a}{2}\left(y^{(r)}(t-1)+y^{(r)}(t)\right) \\
& =\sum_{v=1}^{N-1} b_{v} x_{v}{ }^{(r)}(t-\tau) \\
\left(\frac{a}{2}+1\right) & y^{(r)}(t)=\sum_{v=1}^{N-1} b_{v} x_{v}{ }^{(r)}(t-\tau)-\sum_{v=1}^{t-1} f_{t-v}(-q) \\
& \cdot y^{(r)}(v)-\frac{a}{2} y^{(r)}(t-1) \\
y^{(r)}(t)= & \frac{y_{v=1}^{N-1} b_{v} x_{v}{ }^{(r)}(t-\tau)-a y^{(r)}(t-1)}{a-1} f_{t-v}(-q) \cdot y^{(r)}(v)-\frac{a}{2} y^{(r)}(t-1) \\
y^{(r)}(t)= & \frac{a}{2}+1 \\
& \sum_{v=1}^{N-1} b_{v} x_{v}{ }^{(r)}(t-\tau)-2 \sum_{v=1}^{t-1} f_{t-v}(-q)
\end{aligned}
$$

As Eq. (5) has proved, the model predicted value is:

$\hat{y}^{(r)}(t)=$

$\frac{2 \sum_{v=1}^{N-1} b_{v} x_{v}{ }^{(r)}(t-\tau)-2 \sum_{v=1}^{t-1} f_{t-v}(-q) \cdot y^{(r)}(v)-a y^{(r)}(t-1)}{a+2}$.

The model-restored value is:

$$
\hat{y}^{(0)}=P^{-r} \hat{y}^{(r)} \text {. }
$$

\subsection{Calculation of the error of the model}

The error of the model is an important measure of the reliability and practicability. The error of the model is mainly represented by the percentage of average absolute error (MAPE), and the formula [37] is:

$$
M A P E=\frac{1}{m} \sum_{t=1}^{m} \frac{y^{(0)}(t)-\hat{y}^{(0)}(t)}{y^{(0)}(t)} \times 100 \% \text {. }
$$

It is clear that the larger the $M A P E$ value of the model is, the lower the reliability and practical value of the model will be.

$$
\hat{y}^{(r)}(t)=\frac{2 \sum_{v=1}^{N-1} b_{v} x_{v}{ }^{(r)}(t-\tau)-2 \sum_{v=1}^{t-1} f_{t-v}(-q) \cdot y^{(r)}(v)-a y^{(r)}(t-1)}{a+2}
$$




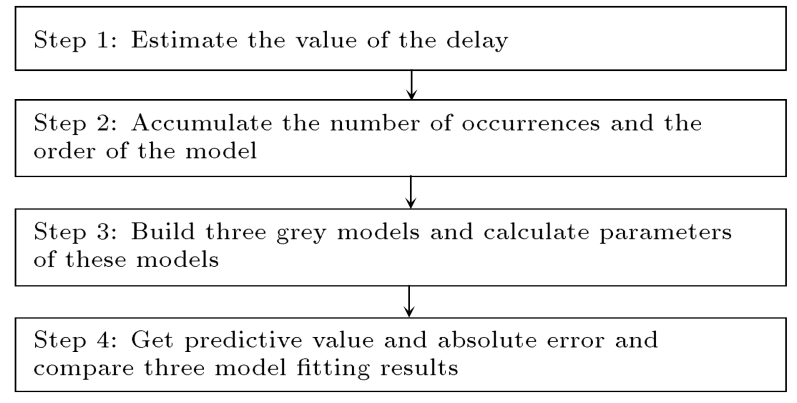

Figure 4. Steps of experimental results.

Figure 4 is plotted to make the example analysis clearer. In Section 5, the steps shown in Figure 4 are followed.

\section{Experimental results}

Conventional investing wisdom dictates that when the dollar strengthens, oil prices fall. The logic behind it is that when a commodity becomes more expensive, people buy less of it. However, that is a backward way of thinking about the relationship between the two assets, said Doug Borthwick, the head of foreign exchange at Chapdelaine \& Co [39]. It is not the dollar's movement that drives oil. In this paper, data have been collected to study the relationship between oil prices and exchange rates quantitatively with a mathematical method.

Data were collected from June 1, 2015 to June 12, 2015 and comprise 12 days of data concerning the US dollar against the RMB exchange rate and Brent oil price data. These data are presented in Table 2 .

To compare our experimental results, four steps will be followed:

Step 1: Estimate the value of the delay. As shown in Figure 3, the exchange rate as the reference sequence, $y$, and Brent oil prices as the comparison sequence, $x$, we can get the following analysis of the delay coefficient.

The data marked in black, shown in Table 3, include the maximum grey correlation of each column. It can be seen that the maximum degree of correlation of each row is 4 days; therefore, it can measure the lag of the oil price relative to the exchange rate. It takes 4 days before exchange rate changes in the oil price are reflected.

Step 2: Accumulate the number of occurrences and
Table 3. Grey correlation between exchange rate and oil price.

\begin{tabular}{cc}
\hline Time delay & Grey correlation with time delay \\
\hline 0 & $0.523,0.423,0.370,0.474$ \\
1 & $0.631,0.554,0.529,0.573$ \\
2 & $0.705,0.651,0.598,0.682$ \\
3 & $0.762,0.723,0.606,0.713$ \\
4 & $\mathbf{0 . 8 5 2}, \mathbf{0 . 7 6 4}, \mathbf{0 . 6 8 3}, \mathbf{0 . 7 5 6}$ \\
5 & $0.673,0.586,0.523$ \\
6 & $0.606,0.551$ \\
7 & 0.610 \\
\hline
\end{tabular}

the order of the model. The fractional $G M(q, N, \tau)$ model is the expansion and supplement of the $G M(1, N)$ model. This paper mainly improves the following two aspects. First, the fractional-order accumulation replaces the classical one-time cumulative generation. Second, in the differential equation order of the model, the fractional differential equation is used. For this fractional $G M(q, N, \tau)$ model, the number of cumulative generation, $r$, and the order of differential equations, $q$, need to be calculated.

The absolute error percentage of the model (abbreviated $M A P E$ ) is often used to evaluate the model; therefore, the model with the smallest $M A P E$ with respect to $r$, and $q$ is considered as the optimal model. The minimum value of $M A P E$ to optimize the target, and the establishment of $M A P E$ on $r$ and $q$ optimization model can be expressed as follows [37]:

$$
\min M A P E=\frac{1}{m} \sum_{t=1}^{m} \frac{y^{(0)}(t)-\hat{y}^{(0)}(t)}{y^{(0)}(t)} \times 100 \% \text {. }
$$

Since the calculation of $M A P E$ involves absolute value sign operations, $M A P E$ is not derivable for $r$ and $q$. It is difficult to obtain the optimal expression of the model by formula. In this paper, the particle swarm optimization algorithm is used.

Step 3: Establish three grey models and calculate parameters of these models. Based on Eq. (1), take the data in Table 4 is taken as an example, $\tau=4$.

Using FAGM $(q, 2,4)$ model in combination with the particle swarm optimization algorithm and the $M A P E$ value as the minimum target, the optimal number of times of the search is $r=9372$, the order of the optimal differential equation is $q=1.9361$, and the model parameters are $a=0.0018$, and $b=0.0171$. The prediction model obtained according to Eq. (1) is:

Table 2. Trend chart of oil price and exchange rate in 2015.

\begin{tabular}{ccccccccccccc}
\hline & \multicolumn{10}{c}{ Data: June 1, 2015 to June 12, 2015 } \\
\cline { 2 - 14 } & $\mathbf{1}$ & $\mathbf{2}$ & $\mathbf{3}$ & $\mathbf{4}$ & $\mathbf{5}$ & $\mathbf{6}$ & $\mathbf{7}$ & $\mathbf{8}$ & $\mathbf{9}$ & $\mathbf{1 0}$ & $\mathbf{1 1}$ & $\mathbf{1 2}$ \\
\hline Exchange rate & 0.192 & 0.091 & 0.000 & 0.293 & 0.545 & 0.545 & 0.545 & 0.869 & 0.747 & 0.697 & 0.848 & 1.000 \\
Brent & 0.583 & 0.645 & 0.562 & 0.000 & 0.005 & 0.005 & 0.005 & 0.228 & 0.666 & 1.000 & 0.788 & 0.657 \\
\hline
\end{tabular}


Table 4. Exchange rate and Brent oil prices.

\begin{tabular}{|c|c|c|c|c|c|c|c|c|c|c|c|c|}
\hline & \multicolumn{12}{|c|}{ Data from April 1, 2008 to April 12, 2008} \\
\hline & 1 & 2 & 3 & 4 & 5 & 6 & 7 & 8 & 9 & 10 & 11 & 12 \\
\hline Exchange & 620.0 & 619.9 & 619.8 & 620.1 & 620.4 & 620.4 & 620.4 & 620.7 & 620.6 & 620.5 & 620.7 & 620.8 \\
\hline Brent & 62.9 & 63.1 & 62.8 & 60.3 & 60.4 & 60.4 & 60.4 & 61.3 & 63.2 & 64.7 & 63.8 & 63.2 \\
\hline
\end{tabular}

Table 5. Comparison of the prediction results of three multi-variable grey models.

\begin{tabular}{|c|c|c|c|c|c|c|}
\hline \multirow[b]{2}{*}{$\begin{array}{l}\text { Real } \\
\text { data }\end{array}$} & \multicolumn{2}{|c|}{$\operatorname{GM}(1,2)$} & \multicolumn{2}{|c|}{$G M(1,2,4)$} & \multicolumn{2}{|c|}{$F A G M(q, 2,4)$} \\
\hline & $\begin{array}{c}\text { Predictive } \\
\text { value }\end{array}$ & $\begin{array}{c}\text { Absolute } \\
\text { error }\end{array}$ & $\begin{array}{c}\text { Predictive } \\
\text { value }\end{array}$ & $\begin{array}{c}\text { Absolute } \\
\text { error }\end{array}$ & $\begin{array}{c}\text { Predictive } \\
\text { value }\end{array}$ & $\begin{array}{c}\text { Absolute } \\
\text { error }\end{array}$ \\
\hline 620 & 620 & $0.000 \%$ & 620 & $0.000 \%$ & 620 & $0.000 \%$ \\
\hline 619.9 & 628.1707 & $1.334 \%$ & 634.1636 & $2.301 \%$ & 619.8145 & $0.014 \%$ \\
\hline 619.81 & 630.9555 & $1.798 \%$ & 614.1588 & $0.912 \%$ & 619.9286 & $0.019 \%$ \\
\hline 620.1 & 607.2079 & $2.079 \%$ & 610.3393 & $1.574 \%$ & 620.084 & $0.003 \%$ \\
\hline 620.35 & 606.7265 & $2.196 \%$ & 598.5198 & $3.519 \%$ & 620.2309 & $0.019 \%$ \\
\hline 620.35 & 606.7128 & $2.198 \%$ & 626.6881 & $1.022 \%$ & 620.35 & $0.000 \%$ \\
\hline 620.35 & 606.7124 & $2.198 \%$ & 628.0715 & $1.245 \%$ & 620.4321 & $0.013 \%$ \\
\hline 620.67 & 616.1845 & $0.723 \%$ & 628.1394 & $1.203 \%$ & 620.4888 & $0.029 \%$ \\
\hline 620.55 & 635.0082 & $2.330 \%$ & 625.4003 & $0.782 \%$ & 620.5488 & $0.000 \%$ \\
\hline 620.5 & 649.704 & $4.707 \%$ & 627.8191 & $1.180 \%$ & 620.6324 & $0.021 \%$ \\
\hline 620.65 & 641.1389 & $3.301 \%$ & 624.5334 & $0.626 \%$ & 620.7199 & $0.011 \%$ \\
\hline 620.8 & 635.3287 & $2.340 \%$ & 601.2974 & $3.142 \%$ & 620.8 & $0.000 \%$ \\
\hline$M A P E$ & \multicolumn{2}{|c|}{$2.1 \%$} & \multicolumn{2}{|c|}{$1.459 \%$} & \multicolumn{2}{|c|}{$0.011 \%$} \\
\hline
\end{tabular}

$$
\begin{aligned}
y^{(-0.9989)}(t) & +0.0018 Z_{y}^{(0.9372)}(t) \\
& =0.0171 x^{(0.9372)}(t-4) .
\end{aligned}
$$

The absolute percentage error of the model is $M A P E=1.0827 \times 10^{-4}$.

With the parameters of the $G M(1,2,4)$ model ( $a=1.8127$, and $b=18.0283)$, the model is:

$$
y^{(0)}(t)+1.8127 Z_{y}^{(1)}(t)=18.0283 x^{(1)}(t-4) .
$$

The absolute percentage error of the model is $M A P E=1.46 \times 10^{-2}$. With the parameters of the $G M(1,2)$ model $(a=1.8892$ and $b=18.9891)$, the model is:

$$
y^{(0)}(t)+1.8892 Z_{y}^{(1)}(t)=18.9891 x^{(1)}(t) .
$$

The absolute percentage error of the model is $M A P E=2.1 \times 10^{-2}$.

Step 4: Compare three model fitting results. Based on Table 5, we can determine that the fitting results of $\operatorname{GM}(1,2,4)$ are good, which can also be seen in Figure 5. In addition, $M A P E$ of $G M(q, N, \tau)$ is max, and $F A G M(q, 2,4)$ is min, suggesting that changes of oil prices and exchange rate are not synchronized. Therefore, fractional-order grey model has better

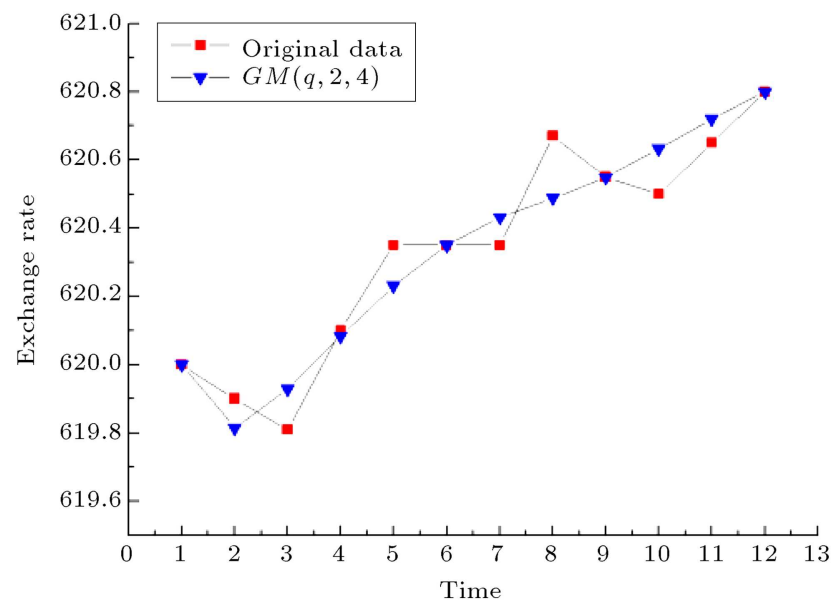

Figure 5. The comparison of original data and predictive data by $G M(q, 2,4)$.

functionality, which can be seen in Figures 6 and 7 . By comparison, the absolute error of $F A G M(q, 2,4)$ is minimal, which can be seen in Figure 8.

To make this paper more persuasive, data from April 1, 2008 to April 12, 2008 were selected comprising of 12 days of data concerning the US dollar against the RMB exchange rate and Brent oil price data.

Comparing Table 5 and Table 6, this study de- 


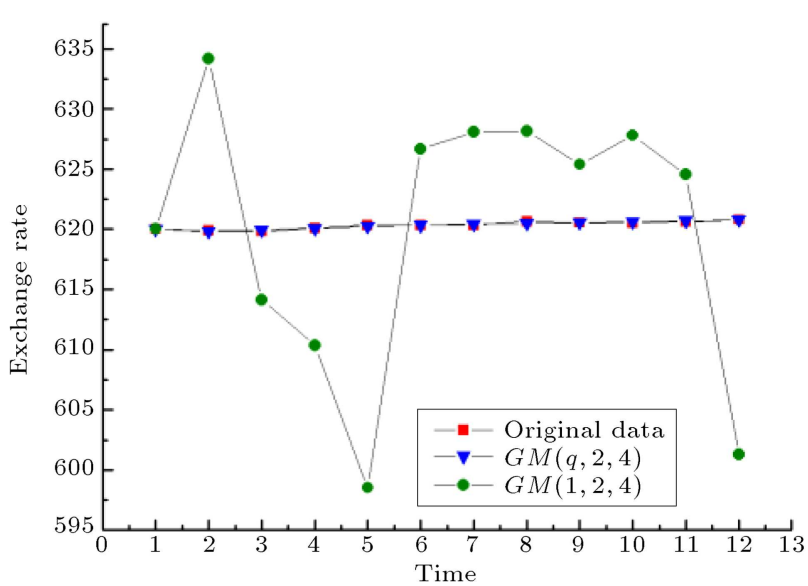

Figure 6. The comparison of original data and predictive data by $G M(q, 2,4)$ and $G M(1,2,4)$.

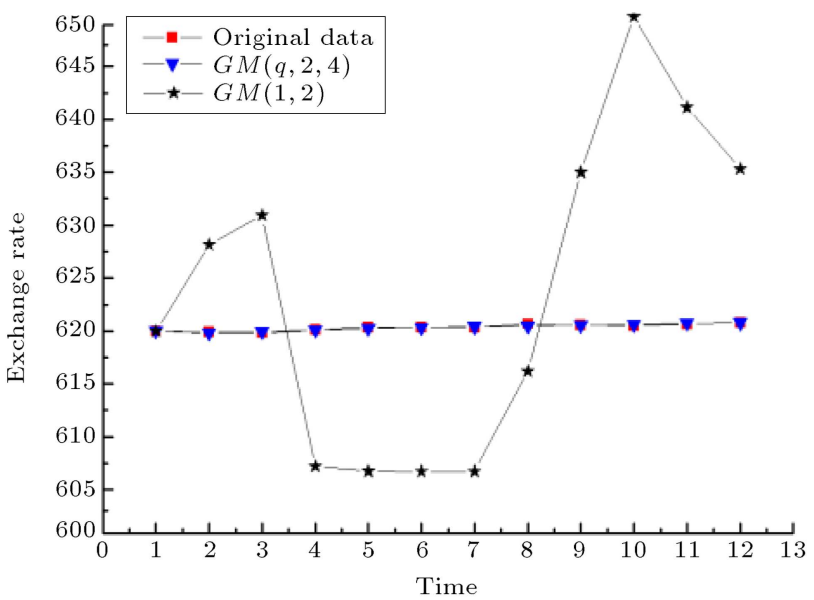

Figure 7. The comparison of original data and predictive data by $G M(q, 2,4)$ and $G M(1,2)$.

termined that the proposed model could be applied to more periods including the new state of economy. The absolute error percentage of the model (abbreviated as $M A P E$ ) is often used to evaluate the model; this model has the minimum $M A P E$. A fractional-order

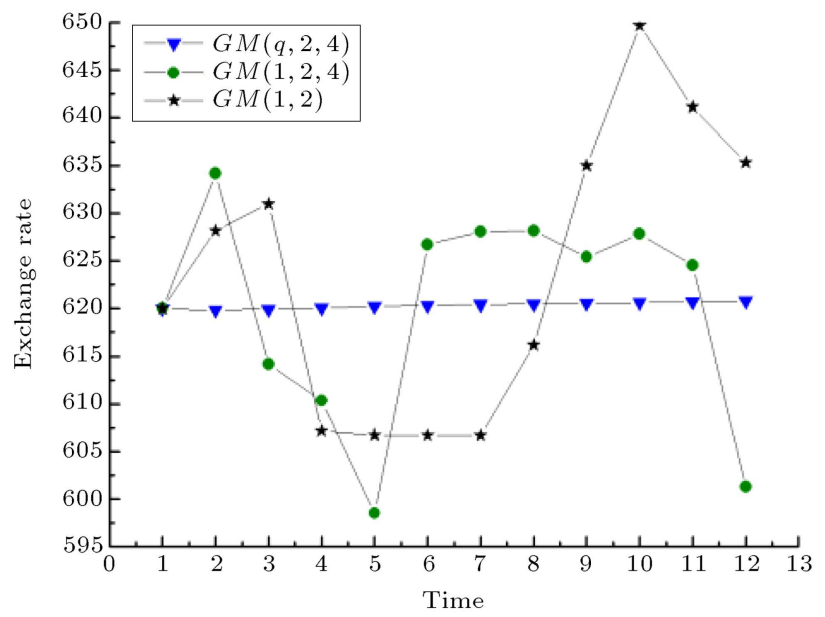

Figure 8. The comparison of predictive data by $G M(q, 2,4), G M(1,2,4)$, and $G M(1,2)$.

grey model was established with lags to study the correlation between Brent oil price and exchange rate, considering time delay in real situations and improving the reliability and practicability of the model.

\section{Conclusions}

So far, many methods have been used to study the correlation between oil price and exchange rate. When considering special periods, we only have limited data to establish models, thus making autoregressive model inapplicable. Moreover, the real situation is even more complex. Accordingly, the grey model was established. The traditional grey model was improved to become the fractional-order grey model with lags, closer to the real situation. The results showed that our absolute error is min, which can be applied to practice.

This paper established a fractional $\operatorname{GM}(q, N, \tau)$ model to research the correlation between oil price and exchange rate. This grey model was improved in comparison with the traditional grey model. Moreover,

Table 6. Comparison of $F A G M(q, 2,4)$ and $G M(1,2)$ model.

\begin{tabular}{|c|c|c|c|c|}
\hline \multirow[b]{2}{*}{ Real data } & \multicolumn{2}{|c|}{$G M(1,2)$} & \multicolumn{2}{|c|}{$F A G M(q, 2,4)$} \\
\hline & Predictive value & Absolute error & Predictive value & Absolute error \\
\hline 701.20 & 701.20 & $0.00 \%$ & 701.20 & $0.00 \%$ \\
\hline 701.89 & 743.60 & $5.94 \%$ & 702.08 & $0.03 \%$ \\
\hline 701.75 & 656.12 & $6.50 \%$ & 701.75 & $0.00 \%$ \\
\hline 701.75 & 676.50 & $3.60 \%$ & 701.15 & $0.09 \%$ \\
\hline 700.15 & 702.38 & $0.32 \%$ & 700.66 & $0.07 \%$ \\
\hline 700.12 & 688.51 & $1.66 \%$ & 700.36 & $0.03 \%$ \\
\hline 700.21 & 711.57 & $1.62 \%$ & 700.14 & $0.01 \%$ \\
\hline 699.2 & 705.24 & $0.86 \%$ & 700.03 & $0.12 \%$ \\
\hline 700.65 & 704.98 & $0.62 \%$ & 699.88 & $0.11 \%$ \\
\hline 699.94 & 714.61 & $2.10 \%$ & 699.76 & $0.03 \%$ \\
\hline 699.25 & 732.87 & $4.81 \%$ & 699.55 & $0.04 \%$ \\
\hline 699.22 & 729.35 & $4.31 \%$ & 699.27 & $0.01 \%$ \\
\hline$M A P E$ & \multicolumn{2}{|c|}{$2.69 \%$} & \multicolumn{2}{|c|}{$0.04 \%$} \\
\hline
\end{tabular}


the results between three grey models were compared. Then, it was determined that oil prices had a positive effect on the rise of the exchange rate; therefore, some recommendations were presented. The contributions of this paper are as follows:

1. $a$ reflects the coordination degree. In the three models, $a>0$, indicating that the exchange rate and oil prices are not coordinated in development, which is consistent with the new economic normal. Thus, in the new economy, it is necessary to adjust the economic structure and improve risk management. $\quad b$ is the coordination coefficient, which reflects the influence of the factor variables on the dynamic change of the behavior variables. In the three models, $b>0$, showing that the oil price has a positive effect on the exchange rate;

2. In the $G M(1,2)$ and $G M(1,2,4)$ models, the value of $a$ is not high, showing that the exchange rate and oil prices have a small degree of coordination. The $b$ value is larger, indicating that oil prices have a greater role in promoting the exchange rate in the new economic normal. This result is inconsistent with the actual situation; however, it can be seen that the average absolute error of the model with lag is smaller, indicating that there is a lag between them. The time-delay grey model can improve the traditional model to describe this causal relationship;

3. The fractal $G M(q, N, \tau)$ model established in this paper considers the hysteresis and the volatility and obtains the higher fitting precision. The average absolute error is the smallest. According to Figure 8, the model fitting value of the fractional cumulant with the real value is more fit and can significantly improve the economic sequence of simulation and prediction accuracy. In the model, $a>0$, reflecting the exchange rate and the development of oil prices were in the uncoordinated state; however, $a$ is small, indicating that the degree of non-coordination is not considerable enough, and $b$ value is significantly reduced, indicating that an increase has a certain role in promoting exchange rate under the new economic conditions. In order to make the exchange rate fluctuations more stable, the support of national policy and economic structure of the adjustment is required, which is practical for the reference value;

4. In this paper, a fractional $G M(q, N, \tau)$ model is proposed based on the multivariable grey system modeling method. The parameter estimation method is given. The time-delay grey correlation analysis is used to solve the delay coefficient of the model. It provides an effective tool to solve the problem, which has time lag causality and a small sample size. Under the new economic conditions, oil and exchange rates do not change in harmony; however, the degree of non-coordination is not considerable enough. Oil prices have a certain role in affecting the exchange rate, yet the impact is not large. In order to make the exchange rate fluctuations more stable, the economic structure should be adjusted. One should have broad prospects for applying the proposed model; in doing so, the simulation and prediction accuracy of economic systems should significantly improve.

\section{Acknowledgements}

This work was supported by a grant from the National Natural Science Foundation of China (Nos. 51479151, 71671135), which facilitated the development of the grey modeling of the ship's power system for the coupling of the navigable environment.

\section{References}

1. Amano, R.A. and Norden, S.V. "Oil prices and the rise and fall of the US real exchange rate", Journal of International Money \& Finance, 17, pp. 299-316 (1998).

2. Akram, Q.F. "Oil prices and exchange rates: Norwegian evidence", The Econometrics Journal, 7, pp. 476504 (2004).

3. Huang, Y. and Guo, F. "The role of oil price shocks on China's real exchange rate", China Economic Review, 18, pp. 403-416 (2007).

4. Babatunde, M.A. "Oil price shocks and exchange rate in Nigeria", International Journal of Energy Sector Management, 9, pp. 2-19 (2015).

5. Sadorsky, P. "The empirical relationship between energy futures prices and exchange rates", Energy Economics, 22, pp. 253-266 (2000).

6. Yousefi, A. and Wirjanto, T.S. "The empirical role of the exchange rate on the crude-oil price formation", Energy Economics, 26, pp. 783-799 (2004).

7. Nakajima, T. and Hamori, S. "Causality-in-mean and causality-in-variance among electricity prices, crude oil prices, and yen-US dollar exchange rates in Japan", Research in International Business \& Finance, 26, pp. 371-386 (2012).

8. Beckmann, J. and Czudaj, R. "Is there a homogeneous causality pattern between oil prices and currencies of oil importers and exporters", Energy Economics, 40, pp. 665-678 (2013).

9. Reboredo, J.C. "Modelling oil price and exchange rate co-movements", Journal of Policy Modeling, 34, pp. 419-440 (2012).

10. Aloui, R., Aïssa, M.S.B. and Nguyen, D.K. "Conditional dependence structure between oil prices and exchange rates: A copula-GARCH approach", Journal 
of International Money \& Finance, 32, pp. 719-738 (2013).

11. Bal, D.P. and Rath, B.N. "Nonlinear causality between crude oil price and exchange rate: A comparative study of China and India", Energy Economics, 51, pp. 149$156(2015)$.

12. Brayek, A.B., Sebai, S., and Naoui, K. "A study of the interactive relationship between oil price and exchange rate: A copula approach and a DCC-MGARCH model", Journal of Economic Asymmetries, 12, pp. 173-189 (2015).

13. Krichene, N. "A simultaneous equations model for world crude oil and natural gas markets", Social Science Electronic Publishing, 5, pp. 32-53 (2005).

14. Zalduendo, J. "Determinants of Venezuela's equilibrium real exchange rate", IMF Working Papers, 6, pp. 74-96 (2006).

15. Ghosh, S. "Examining crude oil price-exchange rate nexus for India during the period of extreme oil price volatility", Applied Energy, 88, pp. 1886-1889 (2011).

16. Basher, S.A., Haug, A.A., and Sadorsky, P. "Oil prices, exchange rates and emerging stock markets", Energy Economics, 34, pp. 227-240 (2012).

17. Shahbaz, M., Tiwari, A.K., and Tahir, M.I. "Analyzing time-frequency relationship between oil price and exchange rate in Pakistan through wavelets", Journal of Applied Statistics, 42, pp. 690-704 (2015).

18. Reboredo, J.C. and Rivera-Castro, M.A. "A wavelet decomposition approach to crude oil price and exchange rate dependence", Economic Modelling, 32, pp. 42-57 (2013).

19. Yang, L., Cai, X.J., and Hamori, S. "Does the crude oil price influence the exchange rates of oil-importing and oil-exporting countries differently? A wavelet coherence analysis", International Review of Economics and Finance, 49, pp. 536-547 (2017).

20. Reboredo, J.C., Rivera-Castro, M.A., and Zebende, G.F. "Oil and US dollar exchange rate dependence: a detrended cross-correlation approach", Energy Economics, 42, pp. 132-139 (2014).

21. Jiang, J.Q. and Gu, R.B. "Asymmetrical long-run dependence between oil price and US dollar exchange rate-Based on structural oil shocks", Physica A Statistical Mechanics \& Its Applications, 456, pp. 75-89 (2016).

22. Li, J.F., Lu, X.S., and Zhou, Y. "Cross-correlations between crude oil and exchange markets for selected oil rich economies", Physica A, 453, pp. 131-143 (2016).

23. Mensah, L., Obi, P., and Bokpin, G. "Cointegration test of oil price and US dollar exchange rates for some oil-dependent economies", Research in International Business and Finance, 42, pp. 304-311 (2017).

24. Tiwari, A.K. and Albulescu, C.T. "Oil price and exchange rate in India: fresh evidence from continuous wavelet approach and asymmetric, multi-horizon Granger-causality tests", Applied Energy, 179, pp. 272-283 (2016).
25. Jammazi, R., Lahiani, A., and Nguyen, D.K. "A wavelet-based nonlinear ARDL model for assessing the exchange rate pass-through to crude oil prices", Journal of International Financial Markets Institutions \& Money, 34, pp. 173-187 (2015).

26. Liu, Y.C. and Yan, Y. "China's macroeconomic analysis and forecasting into the "New Normal State" in China from 2014 to 2015, Journal of Economic Theory and Economics, pp. 5-33 (2015).

27. Deng, J.L., Grey Theory Foundation, Huazhong University of Science and Technology Press (2002).

28. Liu, S.F., Zeng, B., and Liu, J. "Four basic models of $\operatorname{GM}(1,1)$ and their suitable sequences", Grey Systems, 5, pp. 141-156 (2015).

29. Xiao, X.P., Song, Z.M., and Li, F., Grey Technology Foundation and Its Application, Science Press (2005).

30. Xiao, X.P. and Mao, S.H., The Method of Grey Prediction and Decision, Science Press, Beijing (2013).

31. Xiao, X.P., Guo, H., and Mao, S.H. "The modeling mechanism, extension and optimization of grey GM(1,1) model", Appl. Math. Model., 38, pp. 18961910 (2014).

32. Tien, T.L. "The indirect measurement of tensile strength of material by the grey prediction model GMC(1, n)", Measurement Science \& Technology, 16, p. $1322(2005)$.

33. Qiu, W.J. and Liu, S.F. "Discretization structure solution of GM (1, N) model", Systems Engineering and Electronics, 28, pp. 1679-1681 (2006).

34. Huang, Y. and Guo, F. "The role of oil price shocks on China's real exchange rate", China Economic Review, 18, pp. 403-416 (2007).

35. Wang, Z.X. "Grey multivariable GM (1, N) power model and its application", System Engineering Theory and Practice, 9, pp. 2357-2363 (2014).

36. Mao, S.H., Gao, M.Y., Wen, J.H., and Nie, X. "Generalized admissible region of class ratio for fractional order GM(1,1) model", Grey System, 26, pp. 56-68 (2014).

37. Mao, S.H., Gao, M.Y., Xiao, X.P., and Zhu, M. "A novel fractional grey system model and its application", Applied Mathematical Modelling, 40, pp. 50635076 (2016).

38. Mao, S.H., Gao, M.Y., and Xiao, X.P. "Fractional order accumulation time-lag $\operatorname{GM}(1, \mathrm{~N}$, ) model and its application", Systems Engineering Theory and Practice, 35, pp. 430-436 (2015).

39. EB/OL. http://www.marketwatch.com/story/themarket-has-got-the-oil-dollar-relationship-all-wrong2015-05-21 (2015).

\section{Biographies}

Shuhua Mao was born in 1973. He received both his MS and PhD degrees in Applied Mathematics from 
Wuhan University of Technology in 2004 and 2011, respectively. He is a Professor in Wuhan University of Technology. His research interests lie in grey system theory and application and data processing and system optimization of intelligent transportation system.

Qiong He was born in 1991. She received her BS degree in Finance from Wuhan University of Technology in 2014. She is now a graduate student of College of Science in Wuhan University of Technology. Her research interests lie in grey system theory and application in economy and finance.

Xinping Xiao was born in 1965 . He received his $\mathrm{PhD}$ degree in Systems Engineering from Huazhong
University of Science and Technology in Wuhan, China. He is now a Professor and the Deputy Dean of the School of Science, Wuhan University of Technology. He has published three books on grey system and over 100 journal papers. His research interests lie in grey system, systems engineering, and graph theory and control technology.

Congjun Rao was born in Huanggang, China, in 1979. He received an MS degree from Wuhan University of Technology, China in 2006 and received his PhD degree from Huazhong University of Science and Technology, China in 2011. His research interests include supply chain management, auction theory, and decision theory and method. 